\title{
ARTíCULOS
}

\section{ARGELIA ENROCADA EN LA LEGISLACIÓN: DE LA VIOLENCIA POLÍTICA A LA AUTOCENSURA PERIODÍSTICA COMO MAL ENDÉMICO}

\author{
Algeria castled in legislation: \\ From political violence to self-censorship as a journalism endemic disease
}

\author{
Beatriz Alonso \\ Periodista. Doctora en Investigación en Medios de Comunicación \\ beatriz alonso@yahoo.es
}

\section{Cómo citar este artículo/Citation:}

Beatriz ALONSO (2018), "Argelia enrocada en la legislación: de la violencia política a la autocensura periodística como mal endémico", Hispania Nova, 16, págs.. 445-472, DOI: https://doi.org/10.20318/hn.2018.4044
Copyright: (C) HISPANIA NOVA es una revista debidamente registrada, con ISSN II38-7319 y Depósito Legal M 9472-1998. Los textos publicados en esta revista están -si no se indica lo contrario- bajo una licencia Reconocimiento-Sin obras derivadas 3.0 España de Creative Commons. Puede copiarlos, distribuirlos y comunicarlos públicamente siempre que cite su autor y la revista y la institución que los publica y no haga con ellos obras derivadas. La licencia completa se puede consultar en: http://creativecommons.org/licenses/by-nd/3.0/es/deed.es
Resumen: Los medios de comunicación en Argelia, especialmente la prensa privada nacida en los albores de la guerra civil de los años noventa, han sido sometidos bajo el yugo de la violencia política desde casi sus orígenes, tanto por parte de las fuerzas represoras de la Administración como de los grupos armados (sean o no considerados terroristas). En un Estado autoritario como el argelino, los conflictos son exámenes potentes a los que se somete a la prensa, la cual puede ayudar a cimentar la democracia si se les permite a los profesionales trabajar. Una legislación que proteja el ejercicio periodístico es fundamental para garantizar la libertad de información.

Palabras clave: Argelia, prensa, legislación, violencia política, autocensura, libertad.

\begin{abstract}
Media in Algeria, especially the private press was born at the dawn of the civil war of the nineties, have been subdued under the yoke of political violence almost from its origins, by the repressive forces of the Administration and the armed groups, whether or not considered terrorists. In an authoritarian state like Algeria, conflicts are powerful tests. Press can help to found democracy if journalists could work effectively. A legislation to protect the practice of journalism is essential to ensure freedom of information.
\end{abstract}

Key words: Algeria, press, legislation, political violence, self-censorship, freedom. 


\section{Introducción}

El mundo de la segunda década de los años 2000 sobrevive polarizado en muchos sentidos. Mientras en el continente americano se firmaba un acuerdo de Paz de 297 páginas con el objetivo de desarmar efectivamente a la guerrilla colombiana de las FARC e incluir a sus efectivos en la vida social y política poniendo así fin a 52 años de guerra; en la vecina Venezuela se suceden las protestas callejeras convocadas por la opositora Mesa de Unidad Democrática (MUD) para enfrentar un autogolpe del Gobierno —según alega la alianza- llevado a cabo mediante controvertidas decisiones del Tribunal Supremo y con la llamada del presidente Nicolás Maduro a instalar una Asamblea Nacional Constituyente a su medida.

En el otro lado del Atlántico, el foco se encuentra detenido en Oriente Medio, allí donde está ocurriendo el drama humanitario más grave desde la Segunda Guerra Mundial: la guerra en Siria y en Irak. A veces ese foco se gira para prestar atención a otras guerras, como la de Yemen o Libia, pero no suele mirar más hacia el oeste. Sin embargo, países como Argelia, en calma aparente, no difieren mucho en la base de homónimos lejanos como Venezuela. En ambos países, la población está dividida en dos. En Argelia, en concreto, se encuentran los que apoyan incondicionalmente al presidente Bouteflika, por una parte; y los que le quitan la responsabilidad de los fallos y carencias del sistema mientras culpan a los mandos medios (quienes paradójicamente son elegidos por el mismo presidente, aunque este detalle sea obviado), por otra. En ambos países, existe un problema de independencia del poder judicial y no es posible garantizar los derechos civiles y políticos de la población. ¿Existe una solución viable que no degenere en el caos y la violencia?

Seis años después de las revueltas árabes, los atentados de Al Qaeda y la Organización Estado Islámico, la más fuerte de las hijas bastardas gestada por el 
wahabismo de Arabia Saudí ${ }^{1}$, continúan sembrando el terror en torno al Mediterráneo. Su impacto, así como el contrapunto de violencia ejercido por los Estados-Ejército, sigue condicionando el día a día de la población.

Actualmente, en Argelia, existe una parte de la población en contra del sistema, pero es silenciosa; la otra parte, muy comprometida con el régimen, saldría a la calle si se tocase al presidente. Esa es una de las razones por las que no funcionaron las citadas revueltas árabes: los intereses de muchos estaban en juego. Por ese motivo, el poder permite que los argelinos discordantes "ladren", como se dice coloquialmente, porque tienen el compromiso de la mayoría y el apoyo de las potencias que se benefician de los acuerdos económicos y de cooperación, sobre todo en cuestiones de hidrocarburos e infraestructuras. Estos gobiernos extranjeros no se preocupan de investigar si son reales los datos que el Estado argelino provee sobre la situación de los derechos humanos, aunque este hecho conlleve ir en contra de la moral política. Así, Argelia da una apariencia de libertad y respeto por los derechos humanos de cara a la galería ${ }^{2}$. Nada más lejos de la realidad.

En el marco de este artículo, se aborda el concepto de violencia política ejercida por el poder gubernamental, las fuerzas de seguridad o los servicios de inteligencia, por una parte; y los grupos armados considerados o no terroristas, por otra. Todos han ejercido y continúan ejerciendo la violencia política en sus múltiples variantes contra los medios de comunicación argelinos y sus profesionales ${ }^{3}$. Esta situación les desvía irremisiblemente de su labor. Una de las funciones de los medios es legitimar al resto de poderes ${ }^{4}$ a través del control y de la vigilancia crítica ${ }^{5}$. Si pueden realizar su trabajo

\footnotetext{
1 Javier Martín, “Prólogo. La sombra ilusoria de Tamerlán”, David PEREJIL, ¿Qué queda de las revueltas árabes?, Madrid, Catarata, 2015, pág. 17.

${ }^{2}$ Riyad HAMADI, “ Droits de l'Homme en Algérie : le tableau idyllique de Lamamra à Genève”, Tout Sur l'Algérie, (08/05/2017), recuperado de https://www.tsa-algerie.com/droits-de-lhomme-en-algerie-letableau-idyllique-de-lamamra-a-genevel.

${ }^{3}$ Para este artículo se considera oportuno focalizar sobre la prensa. En Argelia siempre ha sido el medio de comunicación por excelencia y, aún en la actualidad, es el soporte de referencia ya que la liberación del sector audiovisual solo se comenzó a emprender a partir de 2011, creándose cadenas de televisión privadas bajo un régimen incierto. Estos nuevos canales no fueron legales, sino tan solo "tolerados" (con la indefensión que ese estatus implica) hasta la publicación de la ley n 14-04 del 24 Rabie Ethani 1435 correspondiente al 24 de febrero de 2014 relativa a la actividad audiovisual, que las autorizó definitivamente.

${ }^{4}$ Ejecutivo, legislativo y judicial.
} 
informativo y de análisis, los medios ejercen una tarea muy delicada de selección del hecho noticioso, que implica magnificar o empequeñecer cualquier acontecimiento hasta hacerlo noticia de portada o condenarlo a la inexistencia, siguiendo el principio de entropía, es decir, la incertidumbre existente ante un conjunto de mensajes, de los cuales se va a recibir uno solo. El Gobierno argelino utiliza mecanismos de coacción y manipulación para minimizar dicha incertidumbre y conseguir que el mensaje permanezca en concordancia con una opinión pública mayoritaria orquestada por el poder estatal, además de intentar que no se vea amenazado por otros mensajes que posibiliten el debate fuera de los márgenes difusamente establecidos. La promulgación de leyes de apariencia democrática muy discutible o "sobornos" a la población para calmar sus reivindicaciones a partir de reformas insuficientes son la cara más "amable" de este tipo de prácticas. Así, las voces que dirigen los medios tienen más posibilidades de influir en la audiencia.

Con este artículo se pretende consignar con hechos las dificultades que implica el ejercicio de la profesión periodística en Argelia. La violencia que ha asolado el país desde su concepción, forjó a fuego y sangre la idiosincrasia del gremio. En la actualidad, la llama del miedo aviva la autocensura, que ha sido conformada a golpe de un mazo legislativo comandado por el poder real, y cuya interpretación es normalmente incierta. De esta forma, se consigue violar constantemente el derecho a la libertad de información.

\section{El miedo como condicionante del tratamiento de la información}

La tortura "toma con el paso de los años una amplitud inconcebible. Practicada en decenas de puestos de detención a jóvenes o viejos, mujeres o niños, pone en práctica al mismo tiempo las técnicas más sofisticadas y las más bárbaras"6. En este ambiente le tocó vivir sus primeros años a la recién nacida prensa independiente argelina, criada en los infiernos de la guerra civil de los años noventa, durante la

\footnotetext{
${ }^{5}$ Jürgen HABERMAS, Historia y crítica de la opinión pública. Barcelona, Gustavo Gili, 1981.

${ }^{6}$ Djallal MALTI, La nouvelle guerre d'Algérie. París, La Découverte, 2001.
} 
llamada década negra, donde la sangre de los impactos se mezcló con la tinta impresa.

Los grupos armados golpearon con terrible crueldad, mientras la policía llevaba a cabo una represión ciega más allá de las filas islamistas y terroristas ${ }^{7}$. El horror cicatrizó en la sociedad. Utilizando este tipo de prácticas, el miedo se convierte en una señal que indica una enorme desproporción entre la amenaza a enfrentar y los recursos de los que se dispone para resolverla ${ }^{8}$. Los profesionales de los medios de comunicación de esa época solo tenían tres opciones de movimiento: exiliarse, claudicar o resistir.

Los que decidieron quedarse o no tuvieron la posibilidad de elegir, y quisieron seguir acometiendo su trabajo, fueron situados en el punto de mira del campo de batalla, entre la trinchera del Ejército y las de los múltiples grupos armados. Se recupera entonces la atmósfera psicológica de guerra total, construida sobre el psicotrauma colectivo heredado de la guerra de Colonización (1830-1848) y de la guerra de Independencia (1954-1962) ${ }^{9}$. La respuesta que se produce en estos casos en relación con las emociones en general, y con el miedo en particular, se traduce en que este miedo no sólo se siente, sino que además produce una reacción interna. $Y$ esto genera una segunda emoción, es decir, una doble reacción. El miedo no es un instante estático, sino una secuencia pautada desde el registro de una amenaza, pasando por la reacción de miedo, hasta llegar a la respuesta interior a esa reacción. Esa respuesta interior al miedo tiene mucha importancia, porque según sea su calidad, actuará atenuando o agravando el miedo original ${ }^{10}$.

Los medios de comunicación son agentes fundamentales en la gestión de la seguridad. Una de sus funciones es representar los conflictos de la sociedad, dar visibilidad a los sujetos que se interrelacionan en ella, explicar las atmósferas y los contextos en los que se inscriben los sucesos, ubicar los acontecimientos dentro de los imaginarios colectivos y proveer a la audiencia de referentes para la comprensión e

\footnotetext{
${ }^{7}$ Benjamin STORA, La gangrène et l'oubli. La mémoire de la guerre d'Algérie, París, La Découverte, 1991.

${ }^{8}$ Noberto LEVY, La sabiduría de las emociones, Barcelona, Plaza y Janés, 2001.

${ }^{9}$ Frantz FANON, Les damnés de la terre, París, La Découverte, 2002.

${ }^{10}$ Noberto LEVY, La sabiduría..., op. cit., pp. 8-9.
} 
interpretación de los hechos ${ }^{11}$. En los medios, los miedos y la percepción de la inseguridad tienden a cristalizarse a través de perspectivas personales que, poco a poco, pasan a formar parte de la cotidianeidad y se proyectan en la audiencia. De esta forma, el miedo se inserta en un entramado social que se ha construido de forma subjetiva, a través del texto, de la imagen, de sus retóricas y de sus mitologías ${ }^{12}$.

Desde esta perspectiva, a principios de los años noventa, los servicios de inteligencia argelinos intentaron explotar las divisiones internas del Frente Islámico de Salvación (FIS) con el objetivo de contrarrestar el activismo. Asimismo, este poder en la sombra utilizó a la prensa independiente para dirigir una conciencia colectiva temerosa de la amenaza islamista, al empujar a los intelectuales a criticar al FIS, para así aportar legitimidad al golpe de Estado del Ejército tras la anulación de las primeras (y únicas) elecciones libres de manipulación en Argelia, en las que el FIS había resultado vencedor ${ }^{13}$.

Los medios resultan estratégicos para los que diseñan y ejecutan las guerras. En ese contexto, la independencia y la calidad del periodismo se ponen a prueba ${ }^{14}$. Los conflictos son exámenes potentes a los que se somete a la prensa, la cual puede ayudar a cimentar la democracia si se permite a los profesionales hacer gala de rigor $\mathrm{y}$ valentía. Si no, los medios pueden ser recordados como objetos de propagación de propaganda al servicio de cada uno de los bandos, dañando la credibilidad del sector en general ${ }^{15}$.

En Argelia, la prensa resistió a pesar de las bombas explosionadas en sus redacciones o las listas negras repletas de nombres de periodistas próximos a

\footnotetext{
11 Germán Rey, El cuerpo del delito. Representación y narrativas mediáticas de la (in)seguridad ciudadana, Centro de Competencia en Comunicación para América Latina, Colombia, 2005.

12 Sergio RONCALLO DOW, "El miedo hace el mensaje. La prensa escrita y el discurso del miedo: EI Tiempo y El Colombiano", Germán REY, Los relatos periodísticos del crimen, Bogotá, Centro de Competencia en Comunicación para América Latina, 2007, pp. 146-147.

${ }^{13}$ Mohammed SAMRAOUI, Chroniques des années de sang. Algérie : comment les services secrets ont manipulé les groupes islamistes, Dënoel, París, 2003.

${ }^{14}$ Javier Darío RESTREPO, María Teresa HERRÁN, Jesús MARTíN-BARBERO, Germán REY, "Debate 16", Revista de Estudios Sociales, nº 16 (2003), pág. 118.

${ }^{15}$ José María TORTOSA, “Los medios y la guerra", Revista de Estudios Sociales, nº 16 (2003), pág. 57.
} 
ejecutar ${ }^{16}$. En cualquier caso, el terror marcó la conciencia del gremio y delineó sus prácticas. La amenaza constante jugó un papel crucial en "la generación de miedos, en el fortalecimiento de las hegemonías o en las posibilidades de promoción del debate público, en contextos generalmente tomados por las confusiones y la intolerancia" ${ }^{\text {"17 }}$.

En la actualidad, el plan estratégico de acción podría consistir en reequilibrar la relación entre los recursos de los que se dispone y la amenaza real: integrando fuerzas, unificando a los miembros del colectivo y propiciando la colaboración entre ellos, para fomentar la acción desde el incremento de la tranquilidad y la confianza ${ }^{18}$. Así, sería posible transformar el miedo disfuncional ${ }^{19}$, fruto de la experiencia de coacción y coerción en el ámbito laboral, ya sea vivida o transmitida de una generación de profesionales a la siguiente -esta última, hija de la guerra civil- en miedo funcional ${ }^{20}$, que se ocupa de compensar la desproporción. Sanar y traspasar la barrera del terror se traduce en anexionar un miedo con el otro y cruzar el puente que los une ${ }^{21}$.

El problema es que en Argelia solo hay dos únicos sindicatos de prensa. Paradójicamente, estos se reclaman libres y reivindicativos. $Y$ la mayoría de los periodistas lo sienten así, por el hecho de que no pertenecen a la Unión General de Trabajadores Argelinos (UGTA), que está bajo la mano del poder. Sin embargo, que estos dos únicos sindicatos permitidos no pertenezcan a la UGTA, no significa en ningún caso que sean efectivamente libres. Es en este tipo de ejemplos donde se observa cómo la libertad queda reducida a un espacio muy pequeño y restringido: a los periodistas les resulta difícil discernir los horizontes de la libertad. Finalmente, la mayoría están manipulados, adoctrinados para sobrevivir, inconscientes de los conceptos reales del periodismo, de la política, o de la sociedad. No obstante, es

\footnotetext{
${ }^{16}$ Djallal MALTI, La nouvelle..., op. cit., pág. 56.

17 Javier Darío RESTREPO, María Teresa HERRÁN, Jesús MARTíN-BARBERO, Germán REY, Debate..., op. cit., pág. 117.

${ }^{18}$ Noberto LEVY, La sabiduría..., op. cit., pág. 20.

${ }^{19}$ El miedo disfuncional se caracteriza por angustiar, inhibir, desorganizar y bloquear la posibilidad de experimentar y aprender.

${ }^{20}$ El miedo funcional se convierte en una señal que muestra una desproporción entre el peligro a enfrentar y los recursos de los que se dispone.

${ }^{21}$ Noberto LEVY, La sabiduría..., op. cit., pág. 21.
} 
necesario señalar la enorme capacidad de resiliencia de aquellos profesionales que, a pesar de la dificultad, se arriesgan para intentar informar de forma objetiva y rigurosa sobre la realidad política argelina dentro del país.

\section{Los medios de comunicación en la espiral de violencia argelina. Perspectiva histórica focalizada en la guerra civil y repaso a sus antecedentes}

Se pueden concebir muchas formas de imposición de la voluntad de los dominantes a los dominados utilizando la fuerza coactiva. Dependiendo de su empleo, Talcott Parsons — siguiendo la síntesis de Eduardo González Calleja- distinguía tres intenciones: la disuasión, que puede llevarse a cabo a través del apremio o la coacción (fuerza o violencia sobre alguien para obligarlo a que diga o ejecute algo), y la coerción (presión ejercida sobre alguien para forzar su voluntad o su conducta); el castigo o la sanción; y la demostración o capacidad simbólica para dominar utilizando la amenaza o la advertencia ${ }^{22}$.

El uso de la violencia exige justificación siempre que inflija lesiones o daños a personas y bienes. En estados de tipo autoritario, como el argelino, este tipo de actos y estrategias verticales para suprimir la disidencia son considerados violencia política (terrorismo, guerra de guerrillas, asesinato; disturbios y violencia en manifestaciones, protestas y huelgas). ¿Cómo justificar entonces la violencia estatal sin embarrancarse en la teoría de la guerra justa y o en la necesidad de castigo? Los debates filosóficos sobre la capacidad de justificación de la violencia suelen centrarse en las condiciones generales de la justificación moral, considerándose que la violencia política es necesariamente antidemocrática ${ }^{23}$. En concreto, cualquier atentado contra los derechos humanos y fundamentales de una población, cometido por el poder que rige un país, con el fin de conseguir o perpetuar objetivos políticos, es observado en este artículo desde la óptica de la violencia política.

\footnotetext{
${ }^{22}$ Eduardo GONZÁLEZ CALLEJA, "Sobre el concepto de represión", Hispania Nova, n6 (2006), (http://hispanianova.rediris.es/6/dossier/6d022.pdf), (20/08/2016).

${ }^{23}$ Kevin MAGILL, "Justifications for Violence", Lester KURTZ, Encyclopedia of Violence, Peace and Conflict, San Diego-Londres-Boston-Nueva York-Sydney-Tokio-Toronto, Academic Press, 1999, pp. 269 y 276.
} 
En Argelia, la prensa nació libre una vez; si bien sus antecedentes ${ }^{24}$ surgieron ligados a una de las formas de sometimiento entre seres humanos más brutales: el colonialismo, en este caso francés, que comenzó en 1830, y se afianzó en un territorio que fue marcado por la represión, las ejecuciones sumarias, las masacres, las purgas, las torturas o los bombardeos; sobre todo, pero no exclusivamente, durante la guerra de Independencia (1954-1962). Después, vio cercado cualquier intento de desarrollo autónomo durante la dictadura del coronel Houari Boumédiène (1965-1976), cuya marca de identidad fue reprimir a la oposición.

Durante este periodo, la prensa fue utilizada principalemente como instrumento de propaganda. Comenzó entonces a esbozarse un tipo de periodismo de profundo carácter político, con una clara tendencia al sensacionalismo, a la manipulación y a la desinformación, con El Moudjahid ${ }^{25}$ como buque insignia del partido en el poder, el Frente de Liberación Nacional (FLN), y único periódico nacional, como el partido al que representaba.

Acorde con las directrices del sistema, cualquier publicación, partido político u organización que no se adscribiese al nuevo orden político, resultaba irremediablemente ilegal. A partir de este momento, se considera que "el 'diario' [del régimen, El Moudjahid] hace su entrada en la historia de la prensa escrita argelina y contribuye a la formación de una opinión pública nacional"26. El uso de este tipo de mecanismos de actuación aplicados en todos los ámbitos a lo largo del territorio argelino, permite al historiador de la "cuestión argelina" por excelencia, Benjamin Stora, afirmar que es el Estado-Ejército quien dirige realmente el FLN, y no a la inversa ${ }^{27}$; es decir, tal y como se escucha generalmente en las diferentes esferas, tanto pública como privada, se trata de un ejército que posee un estado.

Tras la muerte del presidente-dictador Boumédiène en 1978, otro coronel, Chadli Bendjedid, tomó el relevo; aunque ya desde el principio adoptó un modelo

\footnotetext{
${ }^{24}$ El primer referente, L'Estafette d'Alger, de carácter militar y gubernamental, imprimía sus números en el mismo campo de batalla en el marco de la guerra de la Colonización, gracias a las imprentas importadas por los franceses.

${ }^{25}$ Nace en francés y con todos los honores tres días después del golpe de Estado de Boumédiène.

${ }^{26}$ Achour CHEURFI, La presse algérienne, Argel, Casbah Éditions, 2010.

${ }^{27}$ Benjamin STORA, Histoire de l'Algérie depuis l'indépendence, 1. 1962-1988, París, La Découverte, 1991.
} 
diferente. Sus políticas pretendían la modernización del país a través de la liberación del sector privado y el acceso individual a la propiedad privada, solicitado por el comité central del FLN. Sin embargo, no produjo los resultados esperados, pues fomentó la desigualdad social y la excesiva burocracia administrativa, provocando el fortalecimiento de la corriente islamista y las reivindicaciones bereberes ${ }^{28}$; auspiciado todo ello por la incipiente gestación de una joven élite producida tanto desde la universidad argelina como desde la extranjera, a partir del retorno de la diáspora académica. Esta élite, contemplando la posibilidad de creación de un sector privado, engendró una nueva corriente de pensamiento a través de las producciones científicas en el seno de la universidad así como en el sector emprendedor: una clase media consciente de sus intereses, además de reivindicativa, empezó a despuntar ${ }^{29}$.

A pesar de intentos de represión tan graves por parte del Gobierno, como los llevados a cabo durante la primavera bereber de $1980^{30}$, esta sociedad civil de la Argelia independiente acabó alcanzando su mayoría de edad y comenzó a mostrar en su fuero interno una clara ebullición adolescente. La razón reside en que esta sociedad civil harta de insatisfacción, ya había olvidado los motivos por los que se había sometido a la dictadura, transformados en conformismo agradecido por la libertad (secuestrada) después de la guerra de Independencia ${ }^{31}$.

Así, en 1988, la oposición creciente de la sociedad terminó estallando en forma de revueltas estudiantiles (en primera instancia en las áreas más populares) en el este del país, amenazando con resquebrajar las fisuras de un régimen deficientemente cimentado, en crisis por la creciente degradación de la situación social. La sensación de descontento general se hizo fuerte a pasos agigantados con cada huelga, con cada

\footnotetext{
${ }^{28}$ Ahmed BERBER, "Quince años de multipartidismo en Argelia: la difícil transición", Cristina de la PUENTE y Delfina SERRANO RUANO, Activismo político y religioso en el mundo islámico contemporáneo, Madrid, siglo XXI, 2007, pág. 218.

${ }^{29}$ Abderrahman HADJ-NACER, La Martingale Algérienne, Réflexions sur une crise, Argel, Barzakh, 2011.

${ }^{30}$ La apertura prometida por las autoridades a causa de las revueltas no terminó de materializarse y no se atajaron las demandas sociales a pesar de que se llevasen a cabo ciertas reformas.

${ }^{31}$ Gema MARTíN MUÑOZ, El Estado Árabe: crisis de legitimidad y contestación islamista, Barcelona, Bellaterra, 1999.
} 
demanda cultural, con cada éxito en la creación de organizaciones de derechos humanos; y también con el aumento del islamismo político ${ }^{32}$.

Una nueva forma de esfera política que intenta esquivar las directrices del Estado comienza a formarse, propiciada por el derrumbe de algunas prohibiciones al tiempo que se trataba de construir unas bases sólidas donde se sostuviese el pensamiento crítico. Los profesionales de la comunicación utilizan su arte para fomentar el desarrollo de la opinión pública. Sus pioneros, un grupo de setenta periodistas argelinos, denunciaron en un comunicado ante la agencia internacional de noticias francesa AFP, la prohibición de informar objetivamente, la falta de respeto a la libertad de prensa, y los atentados contra los derechos humanos. Así se produce por primera vez un contra discurso lo suficientemente poderoso como para replantear el principio de unanimidad regente hasta entonces ${ }^{33}$.

El pluralismo y la apertura democrática permiten el alumbramiento de la prensa independiente. Hasta las revueltas de la primavera de 1988, el panorama de la prensa escrita, monopolio del Estado, estuvo integrado exclusivamente por El Moudjahid y AlChaab (editados en Argel y de difusión nacional), An-Nasr (para el Este) y AlDjoumhouria (para el Oeste), además de los vespertinos de la capital: Horizons (en francés) y Al-Massa (en árabe).

En los albores de la década negra (guerra civil) nacen la mayoría de las cabeceras que se imprimen en la actualidad. Se cuentan entonces alrededor de 170 títulos, entre públicos y privados, principalmente redactados en francés. Con el advenimiento del gobierno de Sid Ahmed Ghozali y la caída del procurador de las reformas, el primer ministro Mouloud Hamrouche, las ayudas y subvenciones para la creación de los diarios se esfuman de un plumazo; así como los directores de la Agencia de Prensa Argelina (APS) y de la televisión. Las imprentas y el monopolio del papel se nacionalizan. Se impone la censura. El primer sacrificado será el semanario próximo al depuesto primer ministro Hamrouche, Parcours maghrébins ${ }^{34}$.

\footnotetext{
${ }^{32}$ Benjamin STORA, Histoire..., op. cit. pág. 77.

33 ibídem, pág. 64.

${ }^{34}$ Djallal MALTI, La nouvelle..., op. cit., pág. 37.
} 
Una semana antes de la claudicación forzosa del presidente Chadli y diez días después de la victoria del Frente Islámico de Salvación $(\mathrm{FIS})^{35}$ en la primera ronda de las elecciones legislativas, el ministro de la comunicación, Aboubakr Belkaïd, convoca a la prensa para una "conferencia nacional", con el objetivo de calibrar las posturas en el seno de las redacciones sobre la posibilidad de anular la segunda ronda. De todas formas, la mayoría de las cabeceras ya se habían pronunciado a favor, visto el tono de sus informaciones. Tanto el sector que decide respetar la elección del pueblo, así como el muy minoritario compendio de periódicos que rechazan tomar partido, abogando por la autonomía de la prensa, son en la mayoría de los casos reprimidos, suspendidos; sus periodistas son detenidos ${ }^{36}$ y enviados a cualquiera de los cinco centros de detención (campos de concentración) del sur bajo la mirada impasible de sus compañeros de armas, ya fuese por omisión o por insuficiencia de crítica.

Una vez instaurado el estado de emergencia en 1992, cualquier redacción y cualquier persona que trabajase en ella corría el riesgo de pasar a ser objetivo de las medidas llevadas a cabo por el Gobierno en lo que respectaba al tratamiento de la información "en materia de seguridad". Estas políticas "excepcionales" permitían el embargo de las publicaciones, los registros indiscriminados de sedes y corresponsalías, la detención de los periodistas, la suspensión de las cabeceras -alrededor de 60 entre 1992 y 1997-y la prohibición de publicar piezas informativas sobre violencia política cuya fuente no fuese la agencia nacional de información (APS). Todas estas medidas eran aplicadas sistemáticamente con una simple decisión del ministerio del Interior.

Además, se les "sugiere" a los periodistas una serie de "recomendaciones" para forzar en la conciencia colectiva el rechazo al islamismo, impreso e impregnado en titulares como: "No a la segunda vuelta" (EI Watan, 31/12/1991), "iProhibid todos los partidos religiosos totalitarios y anticonstitucionales! Por la interrupción de las elecciones" (Algér Républicain), "¿Qué de bueno tiene ir? [a la segunda vuelta en las elecciones]" (Le Matin, 02/01/1992) o "La mayoría del pueblo ni siquiera sabe para qué sirven" [las elecciones] (L'Hebdo Liberé). Como contrapunto, ningún comunicado del

\footnotetext{
${ }^{35}$ Los principales diarios del partido, Al Munqidh y Al Forkane, son prohibidos inmediatamente.

${ }^{36}$ Especialmente los periodistas arabófonos sospechosos de colaborar con los islamistas.
} 
FIS fue publicado, particularmente aquellos en los que se denunciaba la violencia indiscriminada del Grupo Islámico Armado (GIA), mientras que las reivindicaciones de los atentados de estos últimos ocupaban con creces el espectro mediático ${ }^{37}$. Bloqueados de facto para el gran público, el Ejército Islámico de Salvación (AIS) edita en 1995 una selección de cartas titulada Mots de vérité (Palabras de verdad), con el objetivo de clarificar la desinformación y condenar las acciones del GIA contra la población civil ${ }^{38}$, además de transmitir el mensaje político del FIS ${ }^{39}$.

Para mostrar el rostro humano de algunas de las víctimas de la tragedia, cabe destacar el atentado fallido contra el director de El Watan, Omar Belhouchet; el asesinato del director de la televisión pública, Mustapha Abada; y de su homólogo en El Moudjahid, Mohamed Abderrahmani; o el del antiguo ministro de la comunicación, Aboubakr Belkaïd. Listas negras enrojecidas con nombres de periodistas circulan por doquier y el GIA no escatima en amenazas. Asimismo, los periódicos sirven como arma arrojadiza entre los detentadores del poder real, que ocupan las páginas de los diarios para culparse unos a otros, sibilina pero contundentemente, desde los medios que ellos mismos controlan ${ }^{40}$.

Por otra parte, la guerrilla islamista también dispone de sus propios mecanismos de difusión, como Radio Wafa, una emisión pirata que divulga durante una escasa media hora a la semana las informaciones sobre la Yihad desde el bando del Movimiento Islámico Armado (MIA); o la televisión pirata que retransmitía reportajes del FIS y predicaciones filmadas de uno de sus líderes, Ali Belhadj. Por otra parte, señalar que tan solo Belhadj y algunos de sus subordinados; además de la cabeza política del partido, Abassi Madani, están dispuestos a hacer declaraciones en los medios ${ }^{41}$. En cuanto a la prensa escrita, numerosos comunicados atribuidos en general al GIA de Djamel Zitouni - no todos ellos autentificados - se publican en órganos de propaganda del movimiento islamista como Al Ansar; o en periódicos arabófonos Iondinenses, como El Hayat o Charq al Awsat. En Internet, proliferan páginas para

\footnotetext{
${ }^{37}$ Djallal MALTI, La nouvelle..., op. cit., pp. 35-38.

${ }^{38}$ EI AIS no emprendía acciones armadas contra civiles; solo actuaba sobre objetivos militares.

${ }^{39}$ Djallal MALTI, La nouvelle..., op. cit., pág. 57.

${ }^{40}$ ibídem, pág. 72.

${ }^{41}$ Michael WILLIS, The islamist challenge in Algeria. A political history, Ithaca Press, Berkshire, 1996.
} 
acceder a sus idearios, cuyos ejemplos más significativos son Hijra International, Fraternité Algérienne de France o IEFE. Además, numerosos videos se envían a las televisiones, que ya se venían ocupando desde 1995 de presentar testimonios de islamistas arrepentidos y de prisioneros huidos de los maquis. La campaña desarrollada por los medios de comunicación -tanto nacionales como internacionales- sobre el régimen de horror que infligen los terroristas islamistas no tiene parangón ${ }^{42}$.

A finales de 1993, la periodista alemana especializada en el norte de África, Monika Borgmann, decide concertar una serie de entrevistas con el también periodista, pero argelino y amenazado de muerte, Said Mekbel. Sus testimonios tan lúcidos como agónicos, no fueron publicados hasta 2008, a consecuencia del impacto emocionalmente colateral que paraliza a la periodista alemana al conocer la noticia del asesinato a sangre fría de Mekbel, tan solo un año después de sus encuentros ${ }^{43}$.

Said Mekbel sabía que iba a morir. También sabía quienes eran los comanditarios del drenaje de su pluma. En las entrevistas, denuncia a los responsables de haber llevado al país a la ruina a través de la corrupción y la violencia: el Ejército y los servicios de inteligencia (concretamente, los generales en el poder, cuyos nombres los periodistas tienen prohibido citar $)^{44}$. Esta dinámica sigue en vigor hasta 2014, cuando un cambio de tendencia se desencadena por la publicación de una entrevista al secretario general del Frente de Liberación Nacional (FLN), Amar Saadani, quien "osa" criticar a un miembro del Departamento de Inteligencia y Seguridad (DRS): el todopoderoso e intocable jefe supremo hasta entonces ${ }^{45}$, el general Mohamed Toufik Mediénè. En sus declaraciones, efectuadas a menos de tres meses de las elecciones presidenciales de abril de 2014, proyecta la voz de la conciencia de la mayoría de la población, constatando la presencia de la seguridad

\footnotetext{
${ }^{42}$ Achour CHEURFI, La presse..., op. cit. pp. 201-202.

${ }^{43}$ Monika BORGMANN, Saïd Mekbel: une mort à la lettre, Tizi Ouzou, Frantz Fanon, 2015.

44 ibídem, pág. 90.

${ }^{45}$ Depuesto de sus funciones en 2015 y reemplazado por otro criminal de guerra no enjuiciado aún, el general Athmane Bachir Tartag.
} 
interior en todas las instituciones, dato que confirma que el poder en Argelia no es civil $^{46}$.

Y nunca lo ha sido. Ni libre. En 1993 se inaugura una fatídica lista de periodistas silenciados por la violencia política, comenzando por Tahar Djaout ${ }^{47}$ y llegando a contar con 107 profesionales privados para siempre de su derecho universal a informar $^{48}$. A ellos se les suman 196 asesinatos políticos contabilizados entre 1992 y $2006^{49}$.

En la obra de Yasmina Khadra, Lo qué sueñan los lobos, se describe con cuidado detalle, tanto pictórico como emocional, un atentado a quemarropa contra un magistrado, en 1994, en la puerta de su casa, en presencia de su hija pequeña ${ }^{50}$. Este asesinato político, a pesar de estar novelado, eriza la piel y despunta las lágrimas del lector consciente de que la realidad, en cualquier conflicto, supera la ficción. Esta violencia endémica comienza a tratarse en el marco de la capitulación del Ejército Islámico de Salvación (AIS), en 1997, la cual se hace oficial en 1999, una vez que Abdelaziz Bouteflika es elegido presidente ${ }^{51}$, siendo el candidato propuesto por los generales en el poder y tras recibir el apoyo de once ministros en ejercicio ${ }^{52}$. presidente Bouteflika, legitimado históricamente por haber sido ministro de Asuntos

${ }^{46}$ Katia MEDHI, "Amar Saadani : “Toufik aurait dû démissionner...", Tout Sur l'Algérie, 03/02/2014, http://www.algeriedz.com/forums/showthread. php?t=307553

${ }^{47}$ Nombre con el que se bautizó a la Maison de la presse de Argel, recinto donde se alojan algunos de los principales periódicos del país, como El Watan, El Khabar o Le Soir d'Algérie.

${ }^{48}$ Lista no exhaustiva compuesta con datos extraídos y comparados de la Fedération International des Journalistes (FIJ), la Asociación Nacional de Familias de Periodistas Asesinados por el Terrorismo (ANFAJAT), Reporteros Sin Fronteras y Algeria-Watch.

${ }^{49}$ En esta lista no exhaustiva de Algeria-Watch no se incluye a los miembros de los servicios de seguridad y a las milicias, ni a muchas de las víctimas de los bombardeos y masacres.

${ }^{50}$ Yasmina KHADRA, À quoi rêvent les loups, Argel, Sédia, 2007.

${ }^{51}$ En estas primeras elecciones del candidato Abdelaziz Bouteflika (apoyado por la UGTA y una gran cantidad de asociaciones nacionales), en principio se presentan: Ahmed Taleb El Ibrahimi (candidato de los islamistas conservadores), Hocine Aït Ahmed (FFS, candidato de los bereberes), Abdellah Djaballah (candidato islamista moderado), Moulud Hamrouche, Yousuf Khatib (candidato independiente) y Mokdad Sifi (jefe de gobierno entre 1993 y 1995, apoyado por una parte del RND). Sin embargo, al pasar los días, la idea de elecciones "modelo" se volatiza, primero por la exclusión de Nahnah (líder del MSP), y después por las sospechas de fraude. Así, finalmente Bouteflika gana unas elecciones donde es el único candidato. Posteriormente, revalida su título en 2004, 2009 y 2014; bajo sospecha de fraude, que es denunciada desde algunos organismos internacionales, y publicada en la prensa privada nacional. La reelección de 2014 fue particularmente contestada por una sociedad civil influenciada por las revueltas árabes.

${ }^{52}$ Ahmed BERBER, Quince..., op. cit., pp. 233. 
Exteriores durante la época de Boumediène, así como por su capacidad de organización ${ }^{53}$, pone en marcha el proyecto de ley para la Concordia Civil ${ }^{54}$, de la que ya se habían establecido las bases con la ley rahma (clemencia) del presidente Liamine Zéroual en 1995.

Aunque la violencia contra la población civil y los profesionales de los medios de comunicación se reduce, continúan registrándose casos como el del corresponsal de El Watan en Tebessa, Abdelhaï Beliardouh, quien se "suicida" en 2002 tras haber sido secuestrado y violentamente agredido por civiles mientras investigaba el presunto apoyo a redes terroristas del presidente de la Cámara de Comercio y de la Industria Nememcha, Saad Garboussi.

\section{La huella de la violencia sobre los profesionales de la comunicación y los atentados contra el derecho a la libertad de expresión en la actualidad}

En 2015 se editaban un gran número de diarios (70 aproximadamente $\left.{ }^{55}\right)$ en árabe, amazigh y francés. De este hecho podría deducirse que el sector presentaba un grado más que aceptable en lo que respecta a libertad de prensa y de expresión. Nada más lejos de la realidad. Multitud de organismos extranjeros han denunciado y denuncian en sus informes la falta de libertades que impera en el país. La Clasificación Mundial de la Libertad de Prensa publicada por Reporteros Sin Fronteras del periodo 2011-2012 mostraba que Argelia había alcanzado el puesto 122 desde el 133, impulsada por los vientos de cambio de la primavera árabe. Sin embargo, se señalaba que los medios de comunicación continuaban siendo víctimas de la represión. En el último informe de 2015, el viento se había reducido a brisa: Argelia estaba en el puesto

\footnotetext{
${ }^{53}$ Louisa DRIS-AIIT HAMADOUCHE, "Politique extérieure et politique intérieure algérienne : la résistance révolutionnaire au service de la résilience autoritaire ?", Maghreb-Machrek, n²21, (2015), pág. 19.

54 CHARTE POUR LA PAIX ET LA RECONCILIATION NATIONALE, (http://www.interieur.gov.dz/Dynamics/frmltem.aspx?html=1\&s =3 ), 2006, (20/09/2015).

${ }^{55}$ Según un estudio realizado por el Instituto Abassa en 2007, publicado por L'Expression, los diarios francófonos y arabófonos de la prensa nacional en papel más leídos son: El Khabar (68\%), Echourouk el youmi (24,7\%), Liberté (21,3\%), El Watan (16,2\%), Le Quotidien d'Oran (10,3\%), Le Soir d'Algérie (9,5\%), L'Expression (1,9\%), El Moudjahid (0,8\%), Akher Saa (0,7\%) y Horizons $(0,6 \%)$.
} 
119, un año después, en el 129; para llegar al 134 en 2016. Así, el país ha vuelto a la misma posición ${ }^{56}$ que ocupaba antes de las revueltas árabes.

Desde 2002 hasta 2016, la violencia contra los profesionales de los medios de comunicación no es de carácter mortal. En diciembre, Mohamed Tamalt, periodista condenado por haber publicado contenidos atacando a ciertos responsables políticos, moría llevando hasta el final una huelga de hambre, causando gran indignación entre la población. Tamalt había sido condenado a la pena máxima de dos años de prisión y a una multa de 500.000 dinares $^{57}$ por "ultraje al presidente de la República y a las instituciones del Estado" ${ }^{58}$. Tamalt no era una amenaza real para el poder, pero su represión hasta el final resulta un castigo ejemplar para el resto.

Muchos periodistas han continuado sufriendo agresiones. En 2013, El Watan denunció casos como los del reportero del diario El Maqaam, Mohamed Hamiane, brutalmente golpeado a conciencia tras haberse identificado como periodista mientras cubría una huelga a una distancia prudencial ${ }^{59}$.

La explosión de Internet expandió la coerción y la coacción hacia nuevos colectivos: los periodistas ciudadanos y los ciberactivistas. Como ejemplo, cabe citar al ciberactivista Abdelghani Aloui, inculpado y detenido en prisión preventiva durante siete meses en 2013 por ultraje, al haber publicado un fotomontaje del presidente Bouteflika; así como por hacer apología del terrorismo, al haberse encontrado mensajes yihadistas en su domicilio y en Internet. Amnistía Internacional juzga el caso como manipulación expresa ${ }^{60}$.

56 REPORTERS SANS FRONTIĖRES, Classement mondial de la liberté de la presse 2016, (https://rsf.org/fr/classement/ ), 2016 (03/10/2016).

\footnotetext{
${ }^{57}$ Al cambio oficial, 1 euro equivale a 120.48 dinares a fecha de octubre de 2016.

58 Salima TLEMÇANI, "Le journaliste Mohamed Tamalt écope de la peine maximale", El Watan, (12/07/2016), (http://www.elwatan.com/actualite/le-journaliste-mohamed-tamalt-ecope-de-la-peinemaximale-12-07-2016-324843 109.php ).

${ }^{59}$ Madjid MAKEDHI, "Les cas d'agression contre les journalistes se multiplient", El Watan, (25/06/2013), (http://www.elwatan.com/actualite/les-cas-d-agression-contre-les-journalistes-se-multiplient-25-06-2013218740 109.php ).

60 AMNESTY INTERNATIONAL, "Algeria: Release blogger held for sharing photos on Facebook", Amnesty International France, (15/10/2014), (https://www.amnesty.org/en/latest/news/2013/10/algeriarelease-blogger-held-sharing-photos-facebook/ ).
} 
En 2012, otro joven bloguero de 23 años, Tarek Mameri, fue condenado a ocho meses de prisión condicional y a una multa de 100.000 dinares por destrucción de bienes, incendio de documentos e incitación al desorden; es decir, por apelar al boicot en las elecciones legislativas de mayo. Según su abogado, Amine Sidhoum, se trata de la condena de un militante de derechos humanos. Este mismo abogado defendió a otro bloguero, Omar Ferhat, de 24 años, acusado por un periodista de la cadena Ennahar TV por injurias y amenazas en el curso de una manifestación islamista, donde se acogió a su derecho a la imagen para rechazar ser filmado. Esta confrontación se transformó en altercado. El diario Ennahar, del mismo grupo, publicó fotos del bloguero, acusándole de apología del terrorismo, mientras que decenas de personas se manifestaban en Argel para reclamar su liberación de la prisión preventiva ${ }^{61}$.

En noviembre de 2015, el caricaturista Tahar Dhejiche fue condenado a seis meses de prisión condicional y 500.000 dinares de multa a causa de un trabajo en el que apoyaba al Comité contra la explotación del gas de esquisto, en el sur del país. Su caso recuerda al de otro caricaturista, Djamel Ghanem, que se enfrentó a una pena de prisión de 18 meses por el mismo delito que los anteriores, habiendo finalmente escapado a la sanción gracias a la presión nacional e internacional ${ }^{62}$. La lista se podría continuar; pero el espacio para estas líneas, a diferencia de los barrotes argelinos, es finito.

La ONG Reporteros Sin Fronteras ha recogido una buena parte de las informaciones y las denuncias de los atentados contra la libertad de expresión y de comunicación, siendo el último caso que registraban el de Okacha Mahda, activista de 29 años, miembro del movimiento de desempleados, y antiguo gerente de un cibercafé, condenado en enero de 2016 a seis meses de prisión condicional y 50.000 dinares de multa por haber compartido y comentado (como tantos otros) en Facebook una fotografía que mostraba a unos policías cargando unas sandías.

61 P. R. "Manifestation à Alger : “Libérez le blogueur incarcéré”, El Watan, (30/03/2014), (http://www.elwatan.com/actualite/manifestation-a-alger-liberez-le-blogueur-incarcere-30-03-2014251209 109.php ).

${ }^{62}$ REPORTEROS SIN FRONTERAS, "RSF condamne la censure des médias et des journalistes en Algérie", RSF, (28/04/2015), (http://rsf.org/fr/actualites/rsf-condamne-la-censure-des-medias-et-desjournalistes-en-algerie ). 
Más allá, el último caso ignominioso acontecido en un medio de comunicación argelino hace referencia al "traslado" del periodista Ahmed Lahri, desde su puesto como presentador del telediario de las 19:00 en Canal Algérie, hasta un "lugar de la redacción" — según explicaba el director general de la ENTV para Tout Sur l'Algériedespués de haber pronunciado el nombre del Abdelaziz Bouteflika sin anteponerlo a "presidente de la República", aseguraba el periódico online basándose en "fuentes seguras" $" 63$, tal y como es habitual en los medios argelinos cuando se tratan temas de seguridad.

Por otra parte, algunos medios digitales como Algerie News, Djazaïr News y L'Authentique, fueron suspendidos por el poder bajo excusa de no pagar las deudas contraídas con la empresa estatal de publicidad (ANEP) ${ }^{64}$. Asimismo, el canal generalista Atlas TV, fue víctima de la suspensión estatal por la cobertura de las manifestaciones de la sociedad civil contra el cuarto mandato del presidente Bouteflika, principalmente las del movimiento Barakat! (¡Ya basta!). Sin embargo, la razón oficial se ampara en que la cadena no tenía la autorización para emitir ${ }^{65}$. El otro caso corresponde al canal arabófono pro islamista El Watan TV ${ }^{66}$. Con base en Londres, emitía desde Chipre hasta que fue suspendido en octubre de 2015 por las autoridades, a causa de sus "propuestas subversivas y por atentar contra símbolos del Estado". Concretamente, es probable que la sentencia se refiera a la retransmisión de una entrevista al ex jefe del Ejército Islámico de Salvación (AIS), brazo armado del FIS, Madani Mezrag, quien, bajo amenazas, exhortaba al presidente Bouteflika a revisar su posición sobre la readmisión del partido islamista en la escena política. Pero el poder argelino no se asusta por nada, y menos por un poco de disidencia. Se trata de un poder que ha sobrevivido a una década de guerra y a una población mayoritaria que apoyaba al FIS y a los grupos armados que no atacaban a los civiles.

\footnotetext{
${ }^{63}$ Hadjer GUENANFA, "Ahmed Lahri définitivement écarté du JT pour ne pas avoir dit « Monsieur le président de la République", Tout Sur l'Algérie, (27/02/2016), (http://www.tsaalgerie.com/20160227/ahmed-lahri-defintivement-ecarte-du-it-pour-ne-pas-avoir-dit-monsieur-lepresident-de-la-republique/ ).

${ }^{64}$ A la Entreprise Nationale de Communication, d'Edition et de Publicité (ANEP) todos los diarios, salvo el El Watan y El Khabar que cuentan con rotativas propias, deben rendirle cuentas, las cuales están siempre en rojo.

${ }^{65}$ David ARNOLD, Mathieu BOCH, y Laure SIEGEL, "Quand le pouvoir serre la bride aux medias", Arte, (16/04/2014), (http://info.arte.tv/fr/algerie-quand-le-pouvoir-serre-la-bride-aux-medias ).

${ }^{66}$ Sin ninguna relación con el periódico El Watan.
} 


\section{La ley y la palabra}

Tomando una definición de Michel Foucault de su Metafísica del poder, se entiende que "el conjunto de las relaciones de fuerza existentes en una sociedad constituye el dominio de la políticas, y que una política es una estrategia más o menos global que intenta coordinar y darles un sentido a estas relaciones de fuerza. (...) decir que "todo es político" quiere decir esta omnipresencia de las relaciones de fuerza y su inmanencia en un campo político" ${ }^{\prime 67}$. En Argelia, aunque algunos profesionales de la comunicación no den su brazo a torcer, en pulso constante con las autoridades, la fuerza sigue aún en manos del poder.

En lo que respecta a la ley que regula el sistema informativo, Argelia vivió su momento de gloria en el marco de la apertura democrática de principios de los años noventa, cuando el gobierno reformista de Mouloud Hamrouche permitió la creación de publicaciones privadas gracias a las subvenciones y ayudas a los periodistas para asociarse y crear sus propios diarios al margen de los oficiales progubernamentales. Así, la ley no 90-07 de 3 de abril de 1990 relativa a la información, consagró la libertad de edición y permitió una prensa privada informativa, plural y diversa; libre para desarrollar un tipo de periodismo que invitase a la reflexión basándose en la práctica del periodismo de análisis e investigación ${ }^{68}$.

Todos los buenos propósitos se hundieron en el pozo de la violencia de la década negra, con las dramáticas consecuencias esbozadas en los puntos anteriores. La violencia política ejercida contra los periodistas conllevó, además de un número muy significativo de pérdidas humanas, la imposición de una férrea autocensura de por vida para los que se quedaron.

Sin embargo, gracias a la presión popular ejercida por el influjo de las revueltas árabes, el 12 de enero de 2012, se publicó la ley orgánica no 12-05 relativa a la información, pretendiendo aliviar el yugo impuesto al sector. No obstante, numerosas críticas a la nueva ley se alzaron por considerarla insuficiente. La Liga Argelina de Defensa de los Derechos Humanos (LADDH), el Colectivo de Familias de

\footnotetext{
${ }^{67}$ Michel FOUCAULT, Metafísica del poder, La Piqueta, Madrid, 1979.

${ }^{68}$ Achour CHEURFI, La presse... op. cit. pág.
} 
Desparecidos en Argelia (CFDA), y el Sindicato Nacional del Personal Autónomo de la Administración Pública (SNAPAP), con el apoyo de la Red Euro-Meditarránea de Derechos Humanos (REMDH) elaboraron un informe analizando las restricciones y condiciones a las que está sujeta la ley, destacando:

- La información ya no se concibe como "el derecho del ciudadano a estar informado de manera completa y objetiva", tal y como recogía el artículo 2 de la ley de 1990, sino como una "actividad".

- Los periodistas deberán acatar ciertas obligaciones -algunas ciertamente subjetivas- como: respetar los símbolos del Estado, no atentar contra la historia nacional, o no publicar contenidos amorales que puedan herir la sensibilidad.

- La limitación de la difusión de información exclusiva a los profesionales del sector convierte en ilegal cualquier intento de periodismo ciudadano.

- El excesivo control en la edición de publicaciones periódicas.

- La arbitrariedad en el órgano de regulación de la prensa escrita, que puede limitar la libertad de expresión y de opinión.

- El derecho de rectificación recae sobre el director de la publicación como único responsable, estando obligado a publicar cualquier rectificación considerada pertinente por una tercera persona en menos de 24 horas.

- Las restricciones a la prensa extranjera bajo la autorización del ministerio de Comunicación.

- Y, aunque desaparece la pena de prisión para los periodistas (que sin embargo si se contempla en el Código Penal), se incrementa la cuantía de las multas, pasando de oscilar entre los 2.000 y los 10.000 dinares, a alcanzar sumas entre los 50.000 y los 200.000 dinares $^{69}$.

69 COLLECTIF DE FAMILLES DE DISPARUS EN ALGERIE (CFDA), LIGUE ALGERIENNE DES DROITS DE L'HOMME (LDDH); SYNDICAT NATIONAL AUTONOME DE L'ADMINISTRATION PUBLIQUE (SNAPAP); SECRETARIAT DU RESEAU EURO-MEDITERRANEEN DES DROITS DE L'HOMME (REMDH), Réformes politiques" ou verrouillage supplémentaire de la société civile et du champ politique ?, http://www.algerie-disparus.org/reformes-politiques-ou-verrouillage-supplementairede-la-societe-civile-et-du-champ-politique-une-analyse-critique/ , 2012, (22/09/2016). 
La suerte de los profesionales de los medios de comunicación está regulada por el Código Penal, en concreto por el artículo 144, que castiga con penas de entre dos años y dos meses de prisión, y de una multa de entre 1.000 y 500.000 dinares, a quienes atenten contra el honor o falten el respeto a la autoridad de cualquier miembro de la Administración pública, sea cual sea el soporte, vía escrita o diseñada, y aunque no se haya hecho público. El artículo 144 bis concreta las penas entre tres y doce meses de cárcel, y las multas entre 50.000 y 250.000 dinares, si el sujeto del ultraje, la injuria o la difamación es el presidente de la República. El artículo 144 bis 1 especifica que las publicaciones periodísticas serán responsables de las obras de los miembros de la redacción. Además, el artículo 146 advierte que, en caso de reincidencia, las penas serán dobladas ${ }^{70}$.

En junio de 2016 se publicó la ley $\mathrm{n}^{\circ}$ 16-02 del 14 Ramadhan 1437 correspondiente al 19 de junio de 2016 completando la ordenanza $n^{\circ}$ 66-156 del 8 de junio de 1966 del Código Penal, en la que se confirmó que se había observado el artículo 144; y aún así no se aplicó ninguna modificación al respecto ${ }^{71}$. Por otra parte, la revisión de la Constitución en febrero de 2016 ayudó considerablemente a reforzar la libertad de expresión. El delito de prensa ya no puede ser castigado con pena de prisión. Actualmente, la Constitución garantiza la libertad de expresión, de manifestación y de reunión; pero siempre se que permanezca dentro del marco de la ley y del respeto de los valores religiosos, morales y culturales de la nación; según reza de forma tan literal como etérea la Carta Magna.

Por otra parte, varios artículos del Código Penal relativos a la difamación o insultos a figuras públicas y las instituciones del Estado, permiten a las autoridades tipificar acerca de informaciones, caricaturas o material presuntamente difamatorio. Así se aporta el arsenal legal necesario para silenciar a periodistas, activistas y bloggers.

\footnotetext{
70 REPUBLIQUE ALGÉRIENNE DEMOCRATIQUE ET POPULAIRE, MINISTĖRE DE LA JUSTICE, “Code Penal", Les Éditions de l'O.N.T.E, Argel, 2005.

${ }^{71}$ LOIS, Journal Officiel de la Republique Algerienne N³7, (http://www.mfctrf.gov.dz/presse/Loi\%201602\%20du\%2019\%20juin\%202016\%20CP.pdf ), 2016, (01/09/2016).
} 
Amnistía Internacional denuncia la dificultad para entender la lógica o la coherencia de la aplicación de la ley ${ }^{72}$.

En Argelia, la libertad de prensa se encuentra condicionada a una evolución de las leyes que reduzca las restricciones para los periodistas, o que concretice al menos la naturaleza de los delitos. La Justicia continúa siendo un mecanismo de represión de libertades, bajo cuyo marco se siguen practicando detenciones arbitrarias y torturas ${ }^{73}$.

\section{Conclusiones}

En un Estado de tipo autoritario como el argelino, ni los medios de comunicación ni sus profesionales pueden ser libres. Según explica Smain Laacher: "La legitimidad de los ocupantes del poder depende de la legalidad de las condiciones de su ascensión al poder; pero también, de su pretensión de no eludir la competición política"74. El presidente argelino Abdelaziz Bouteflika fue exitoso candidato a su propia sucesión por cuarta vez en 2014 , desde su silla de ruedas y sin poder articular si quiera unas palabras de agradecimiento a sus votantes; mientras la oposición, esa que no se hubo retirado y optado por el boicot, denunciaba el fraude.

Realmente no se sabe quien será el candidato a la sucesión de Bouteflika. Quizá sea su propio hermano, Said ${ }^{75}$, a imagen de lo que querían hacer Mubarak en Egipto o Ben Alí en Túnez; o tal y como ocurre en Cuba. Tal vez sea el antiguo primer ministro Ahmed Ouyahia, puesto que se encuentra en el círculo de confianza de los militares, aunque la población no le quiera; o incluso el jefe de la policía nacional, Abdelghani Hamel. Esta situación de incertidumbre se tambalea sobre unos precios del petróleo tan bajos que ya no permiten el grado de estabilidad acostumbrado.

\footnotetext{
${ }^{72}$ Charlotte BOZONNET, "La mort du journaliste Mohamed Tamalt aurait pu être évitée", Le Monde, (13/12/2016), (http://www.lemonde.fr/afrique/article/2016/12/13/la-mort-du-journaliste-mohamed-tamaltaurait-pu-etre-evitee $50481213212 . \mathrm{html}$ ).

${ }^{73}$ COLLECTIF DE FAMILLES DE DISPARUS EN ALGÉRIE (CFDA), Human Rights put Algerian regime to the test. The illusion of change, París, Collective of Families of the Disappeared in Algeria, 2013.

${ }^{74}$ Smaïn LAACHER, Insurrections arabes: utopie révolutionnaire et impensé démocratique, París, Libela, 2012.

${ }^{75}$ Se daría entonces una situación inédita en el país; no siendo además Said Bouteflika miembro de la familia revolucionaria. Sin embargo, su fuerza, ya que no tiene instituciones ni legitimidad, reside en el dinero que ha ido distribuyendo: tiene el mando sobre el tesoro de guerra argelino.
} 
Este opaco sistema está enmarañado a conciencia. Todos los círculos de poder que se benefician de él intentan mantener a toda costa el statu quo. Los generales y altos cargos del Ejército y de los servicios secretos, aunque pueda parecer que han perdido el poder en el ámbito público, siguen presentes en el denominado "cabinet noir", es decir, la cúpula del poder. Sin ellos, Argelia no puede sobrevivir. En este primer círculo de poder se encuentran también los máximos responsables del Frente del Liberación Nacional (FLN). En la capa siguiente, se emplazan las organizaciones satélite, compuestas por la familia revolucionaria: ministros, grandes empresarios ${ }^{76} \mathrm{o}$ presidentes de partidos políticos. Inmediatamente después, hay un tercer círculo: presidentes de organizaciones profesionales, presidentes de asociaciones, jefes de tribus, o jefes de hermandades. Dentro de los círculos intermedios, un número creciente de personas poderosas controla la prensa. Todos estos participantes del poder no tienen por qué tener necesariamente estudios o formación específica; en su mayoría son oportunistas del negocio de la política. Más allá, se continúan constituyendo círculos concéntricos, mediante el relevo de influencias, donde en todos los niveles se pasa y se interioriza el mismo mensaje: "El presidente cuenta contigo". Todos estos círculos tienden a un único movimiento, el del enroque.

De esta manera, se consigue la lealtad y la filiación de todos los estratos poblacionales. Los "contratos" vinculantes con el régimen son actualmente económicos: si estás con ellos, tienes la vida solucionada; si intentas desertar, siempre tienen algo con lo que amenazarte utilizando el chantaje como método de actuación. Se trata de un sistema de compromiso basado en un caciquismo económico. En la mayoría de los casos, quien decide no estar junto al poder, se arriesga a la asfixia económica, al exilio forzoso, o en última instancia, a la muerte. También existe la opción de encontrar un lobby que conceda su protección mientras se da la impresión de que se ejerce la crítica.

Finalmente, la mayoría de la población argelina se adscribe en estos círculos, ya sea por una falta de autoestima, de medios o de necesidad de poder. Así nacen decenas de federaciones, que se pueden convertir en partidos políticos al servicio del régimen, lo que le confiere por tanto una apariencia de pluralidad. La mitad de la

\footnotetext{
${ }^{76}$ Antes de 2007 era raro ver hombres de negocios en el FLN. Actualmente, rondan el 50\%.
} 
población está comprometida con este sistema y corrompida por él. Es el dispositivo de empleo para los jóvenes. De este modo, la mayoría se resigna y acata la máxima: "gastar y callar, para asegurar una buena vida".

A pesar de todo, la novedad de los últimos años, es la multiplicidad de títulos de prensa y de redes sociales, donde se instrumentalizan asuntos de corrupción que aparecen y desaparecen dependiendo de los intereses del momento. Gracias a esta y otras tácticas, los periodistas mantienen la ilusión de la lucha, publicando escándalos que implican al número 4 o 5 de cada círculo de poder. No obstante, estas "exclusivas" de fuentes "anónimas", "creíbles", "contrastadas", "autorizadas", o de cualquier otra denominación indefinida; nunca tocan al presidente, ni a los generales, ni al corazón del poder. Porque nadie puede hacerlo. Siguiendo esta lógica, y aún sin quererlo, los periodistas son manipulados.

Tradicionalmente, la prensa conformaba la opinión pública porque controlaba la ideología a través de la línea editorial. Pero ahora es al revés, a causa de la imposibilidad de verificar las fuentes: cualquier persona puede transmitir información a un periodista y darle una apariencia de veracidad. La mayoría de las informaciones estatales provienen de "fuentes autorizadas concordantes" y todas se basan en los mismos informes de las autoridades, que no se pueden contrastar.

El poder sabe que los periodistas no tienen capacidad de maniobra para cambiar la opinión pública, bien porque no han tenido acceso a una formación específica (los periodistas de más de 40 años vienen la mayoría de estudios de filología), o una formación de calidad; o bien porque no tienen ni medios ni instrumentos para hacerlo. La responsabilidad de informar se encuentra entonces con demasiados condicionantes. En cualquier caso, no debería existir ningún peligro para el periodista si no critica fuera de la protección de la facción del poder que le ampara. Los que eligen esta vía, una vez que encuentran trabajo, descubren que pueden tener algunas ventajas por ser periodistas, y lo aprovechan para pedir favores, créditos, o agilidad burocrática y administrativa en un país donde cualquier trámite puede convertirse en una cruzada.

Las emociones propias de la profesión están entonces reprimidas, reducidas, muy lejos de la práctica de la investigación y del descubrimiento de la verdad que 
caracterizó el nacimiento de la prensa independiente en los años noventa. No existe esa toma de conciencia sobre la responsabilidad que se tiene sobre un mensaje importante que tiene que llegar. Además, salvo los altos cargos, la mayoría vive de forma precaria a causa de los míseros sueldos, lo que les puede abocar a la corrupción o a recibir sobornos.

En este panorama, los jóvenes, tanto periodistas como no, no saben lo que significa la libertad, por eso no la piden. Han crecido en un país violento en el que solo se puede sobrevivir y no se puede hablar de temas controvertidos; por eso no pueden pedir la garantía de derechos civiles y políticos: no tienen cubiertas efectivamente sus necesidades básicas. Así, creen que son libres porque gozan de cierta capacidad de acción, pero en realidad están encerrados entre los parámetros dictados por el poder. Ese mismo poder que les alimenta y les vigila.

Aunque, por supuesto, existen células discordantes; pero no son muy fuertes. Son voces auto formadas, abiertas al mundo, que han estudiado por sus propios medios; que escaparon a ese sistema educativo argelino pensado para embrutecer, y que no forma realmente. Estás células se encuentran en algunas organizaciones dentro de Argelia, animadas por sus ideologías: están por todas partes, y también en el periodismo. Pero son muy pocas: cuando convocan manifestaciones o protestas, no suelen ser más de 200 personas, y siempre están arriesgándose a ser manipuladas por los servicios de inteligencia, como ocurrió con Barakat ! Se les deja hablar, sí, pero no tienen seguimiento por parte de la sociedad, y al final se preguntan "¿para quién estoy luchando?", y se desinflan. La sociedad mira impasible y no se une. Y los movimientos desaparecen por falta de apoyo de una sociedad autocensurada. Cada persona individual tiene un interés propio en mantener el statu quo, mientras intenta sacar su propio beneficio fuera de la norma. Por tanto, resulta muy difícil organizar una oposición real sobre una base de inconsciencia social y política; además de sobre una legislación que se reduce a papel mojado, porque el poder ha hecho siempre lo que ha querido, basándose en la ley y en sus prerrogativas. Si no hay una norma firme, no se pueden garantizar los derechos, da igual cuantas veces se reforme la misma. El poder siempre encuentra una excusa o tergiversa la información o los hechos para conseguir sus objetivos. No hay libertad del poder judicial. Los jueces y los fiscales funcionan con 
Ilamadas telefónicas para satisfacer, aplicando la legislación pertinente, las peticiones del poder, basándose en los hechos que se describen en los informes policiales.

El cambio de sistema, de ocurrir, vendría a través de los nuevos movimientos sociales, como el de los desempleados o el del gas de esquisto; de regiones históricamente potentes y de marcada identidad, como Kabilia y Gardaia. Así, se podría vislumbrar una alianza de identidades entre las diferentes etnias argelinas. Pero dentro del imaginario colectivo nacional, estos grupos están desprestigiados por la propaganda sobre su supuesta permisión de injerencia de la "mano extranjera", que incrusta la idea en la población de que estos movimientos están diseñados para sembrar el caos; cuando realmente lo que buscan es acabar con el statu quo: con la desigualdad y la falta de libertades. Por otra parte, también libran batalla con la amenaza constante de ser denunciados por sus compatriotas o compañeros, o de ser detenidos.

Mientras tanto, argelinos y argelinas viven a la espera en un país que ha hecho creer a todo el mundo que podía vivir a través de una realidad de doble fondo compuesta por una "verdadera-falsa prensa llamada independiente, unos verdaderosfalsos partidos llamados autónomos, asociaciones a sueldo del poder, sindicatos mimados que no representan a los trabajadores..."77. De esta manera, la instauración de una verdadera democracia pluralista dependerá de la evolución de las contradicciones internas del régimen y de los movimientos sociales con capacidad para acelerar dicha evolución ${ }^{78}$, así como de los medios que traten de transmitir la información de la forma más objetiva posible, dejando atrás la violencia que se inyecta en la sociedad enferma por el psicotrauma colectivo a través de plumas que son el "producto integrado de muchas dimensiones de la experiencia humana: la historia personal, el tipo de relaciones que se han tenido a lo largo de la vida, el contexto de desarrollo, el sentido de futuro, los procesos de identificación..." ${ }^{79}$. Estos patrones se sostienen en las redacciones sobre el psicotrauma colectivo, la frustración, la violencia política y la autocensura impuesta por el miedo.

\footnotetext{
${ }^{77}$ Abderrahmane HADJ-NACER, La martingale algérienne. Argel, Barzakh, 2011.

${ }^{78}$ Ramdane REDJALA, L'opposition en Algérie depuis 1962 (tome 1- Le PRS-CNRD- Le FFS), París, L'Harmattan, 1988.

${ }^{79}$ Germán Rey, El cuerpo..., op. cit., pág. 15.
} 
Para poder avanzar, los profesionales de la comunicación deberían poder trabajar desde un marco legal que garantizase su seguridad y fomentase el compromiso deontológico. Un cambio de legislación y de aplicación que proteja efectivamente al periodista es imperativo, para que los asuntos más turbios de del país comiencen a ser revelados no solo por los medios extranjeros. Es necesario recuperar unas redes sólidas, que ya existían y fueron destruidas por la violencia, a partir de la mediación y la confianza. Pequeños granos de arena unidos y estratégicamente colocados pueden desviar la inercia de cualquier engranaje sin que la maquinaría tenga irremediablemente que saltar en pedazos.

La comunicación se puede convertir entonces en el dispositivo simbólico para la participación, en la llave para emprender un proceso de aprendizaje social que propicie la oportunidad de generar espacios de conversación social no intimidantes, sino creativos y solidarios. Al fomentar desde los medios de comunicación el intercambio de experiencias y significados socialmente construidos, se promueve la recuperación de la memoria social y la interlocución ciudadana sobre los actos de los gobernantes, puesto que muchos de los problemas de seguridad son mantenidos cuando la sociedad se disuelve, al ser cortados los flujos de comunicación y verse colapsados los sentidos que cohesionan la pertenencia a la sociedad ${ }^{80}$.

Se confirman, por lo tanto, las hipótesis de partida: las élites en el poder mantienen maniatados por la vía legislativa y la presión económica a los medios de comunicación, condicionando su libertad y grado de contestación, e impidiéndoles desarrollarse. Aunque se hayan llevado a cabo reformas legislativas, ni son tan democráticas como parecen ni satisfacen las demandas sociales. De esta forma, la prensa no consigue el grado de libertad que necesita para desarrollar sus funciones plenamente, porque las prácticas periodísticas fuera de la norma corren el riesgo de ser sancionadas, por lo que solo los medios amparados bajo algún ala del poder y con posibilidades económicas para hacer frente a las sanciones pueden permitirse transgredir el umbral tácitamente pactado de la crítica.

\footnotetext{
${ }^{80}$ ibídem, pág. 77.
} 